\title{
DOS VERSIONES DE UN TEXTO DE ANTONIO ENRÍQUEZ GÓMEZ: UN CASO DE AUTOCENSURA
}

Vivo o muerto, en su país o en el exilio temporal, ya usara su nombre o un seudónimo, la censura acechó siempre a Antonio Enríquez Gómez. Dos ejemplos póstumos - uno de contenido ofensivo y el otro no - serán suficientes para ilustrar la naturaleza del problema en España.

Ya que la Inquisición tenía los medios para identificar al escritor Fernando de Zárate como Enríquez Gómez, pudo, sobre esta base, incluir en el índice de 1707 su obra El Capellán de la virgen. San Ildefonso'. Posiblemente, el Santo Oficio no podía aceptar que un judaizante convicto dramatizara la vida de un santo. Al contrario, el contenido de Las misas de San Vicente

\footnotetext{
${ }^{1}$ Según informa Cayetano de la Barrera y Leirado, Catálogo bibliográfico y biográfico del teatro antiguo español desde sus orígenes hasta mediados del siglo xviii, Madrid, 1860, p. 139, aunque no han encontrado la comedia condenada. Ramón Mesonero Romanos, en la introducción a su obra, Dramáticos posteriores a Lope de Vega, Madrid, 2 ts., 1857-1858, t. 1. p. xxxlii, se niega a aceptar la identificación; denigra la capacidad de Enríquez Gómez y alaba el talento de Zárate: "no se halla semejanza alguna, ni en la trama, ni en los pensamientos, ni en la forma de expresarlos, ni en la versificación, ni en el lenguaje, habiendo, a mi entender, una distancia inmensa entre la pobre imaginación dramática de Enríquez, su mal gusto y lenguaje afectado y con resabios de extranjerismo, y la agudeza y variedad de los planes o intrigas cómicas de Zárate, su robusta elocución y estilo castizo, su gracejo y donosura". A pesar de las protestas de Mesonero, no hay duda de que Enríquez Gómez y Zárate son una y la misma persona. Documentos inquisitoriales del A. H. N., aún inéditos, dan pruebas irrefutables; véase, por ejemplo, Inquisición, "Autos en el secuestro de Antonio Enríquez Gómez", Sevilla, leg. 2067, núm. 25 , "Secuestro de bienes" (1661?), en donde consta que el fiscal que allanó la casa de Enríquez Gómez alias Zárate, "halló debajo de un bufete de nogal unos legajos de comedias y loas", lo que explica la continua publicación de sus obras dramáticas después de su muerte. (Véase también "Tribunal de la corte, Secuestros", leg. 1872, núm. 35, 1674).
} 
Ferrer, otra comedia hagiográfica atribuida a Zárate, pero nunca identificada como de Enríquez Gómez, provocó la condena en 1771. Las autoridades eclesiásticas examinaron el texto y condenaron por heréticos ciertos pasajes que se referían al demonio y a la doctrina cristiana de la redención ${ }^{2}$. Así, en 1708, al salir aprobada, aunque censurada del escrutinio inquisitorial, otra media del dicho "Zárate", El gran médico pintor San Lucas, el censor y dramaturgo José de Cañizares confirmó que "las comedias sagradas piden más cuidado que las plenamente profanas"'s Al parecer, el involuntario converso Enríquez Gómez no había aprendido su catecismo.

En Francia, sus contemporáneos se preocupaban menos por sus ideas religiosas que por sus ideas políticas poco ortodoxas (si se puede separar unas de otras). El embajador plenipotenciario de Portugal, Dom Luis Vasco de Gama, estaba tan furioso, que en 1647 envió un mensajero especial de París a Rouen para que confiscara y destruyera no sólo el ofensivo tratado La política angélica, sino también la prensa de la que había salido ${ }^{4}$. En el pró: logo dirigido al lector, Enríquez Gómez respondió al ataque con sus acostumbrada ironía: "Estos dos Diálogos por justos respectos se pusieron apartes, sacándolos de mi Política y ésta es la causa que empiezan de No. 73, que no a sido yerro sino obligación deuida a

2 A. H. N. Consejo de Censores, "Fernando de Zárate", Seg, 11 (1975), David M. GiTLITZ comenta los aspectos sociológicos de la obra teatral, que está en Comedias escogidas 23 (1665), y señala que "San Vicente Ferrer era el némesis de los judíos españoles del sigloxvi". GLEN DiLle, en "A black man's dilemma in Las misas de San Vicente Ferrer", RNo, 20 (1978), 87-93, repite el estudio de Gitlitz sin referencia alguna a su nombre.

El manuscrito y la carta de Cañizares que la acompaña están en el Instituto del Teatre, Barcelona. La comedia había estado incluida en Comedias escogidas, 40 (1675). Espero, en el futuro, trabajar con más detalle estos dos casos de censura, hasta ahora desconocidos.

${ }^{4}$ Para los detalles de este caso, véanse los artículos de I. S. REvaH, "Un pamphlet contre l'Inquisition d'Antonio Enríquez Gómez: la Seconde Partie de la Política angélica(Rouen, 1647)", REJ, 131 (1962), 83-168, y "Manuel Fernandes de Villarreal, adversaire et victime de l'Inquisition portugaise", Ibérica, 1 (1950), 33-54 y 189-257, datos repetidos por ANTONIO MĀRQUEZ en Literatura e Inquisición en España (1478-1834), 1980, donde menciona la prohibición inquisitorial de La política angélica y de La Torre de Babilonia (Rouen, 1649) en 1707, p. 174 (y en este volumen, pp. 526 ss.). Sobre las actividades políticas de Enríquez Gómez en Portugal, véase mi artículo "Portuguese diplomacy plays a role in the printing of some peninsular works in Rouen in the seventeeth century", $A C C P, 10$ (1976), 523-541; y sobre su pensamiento político, Michéle Gendreau-Massaloux Y CONSTANCE HUBBARD ROSE, 'Antonio Enríquez Gómez et Manuel Fernandes de Villarreal: deux destins parallèles, une vision politique commune", REJ, 136 (1976), 368-387. 
quien lo hordenó" (Ruana, 1647). Aunque pareciera ceder a las órdenes del embajador, publicó el libro entero y lo mandó al rey de Portugal ${ }^{5}$.

El problema al que se enfrentaba Enríquez Gómez al imprimir su obra en Francia y al distribuirla en España era doble. Básicamente, escribía para dos públicos muy diferentes y, por añadidura, tenía que hacer frente a dos tipos de censura. Para evitar dificultades presentes y futuras, se procuró, en 1645 , un recurso que solucionara el problema: publicó dos versiones, un poco diferentes, de un tratado político: Luis dado de Dios: Samuel dado de Dios a Elcaná y Ana. Tanto éxito tuvo la estratagema, que el libro pasó la inspección en ambos países, y el engaño se descubrió trescientos años después, o sea en 1976 cuando llamé la atención sobre la existencia de dos versiones del mismo texto ${ }^{6}$.

Durante su voluntario (y necesario) exilio en Francia, Enríquez Gómez escribió nueve obras. Aunque la impresora Laurens Mauvry de Rouen, ciudad en donde el autor vivió desde 1643 hasta 1649, publicó la mayoría de esos libros, Renato Baudy de París imprimió Luis dado de Dios. El volumen, dedicado a Luis XIV, lleva el imprimatur, la firma del agente del rey y el sello real. Enríquez Gómez firma como "Cauallero de la Orden de su Magestad Christianíssima del áuito de San Miguel", título apropiado para el autor de un reloj de príncipes. La obra es una glosa de Samuel I, en la que Luis XIII y Ana de Austria se comparan a Elcana y Ana, y Luis XIV a Samuel' ${ }^{7}$ El autor utiliza

${ }^{5}$ Ejemplar, Bibliothèque Mazarme. Los dos ejemplares salieron de la prensa de Laurens Mauvry de Rouen en 1647, pero se diferencian en cuanto al título y dedicatoria; el de la Bibliothèque Mazarine tiene por título, $L a$ política angélica sobre el govierno que se deve tener con los reduzidos a la fe catholica, y con los que se apartaron della, está dirigido a los "Príncipes Christianos, Columnas de la Militante Iglesia de Roma", y contiene solamente dos de los cinco diálogos del ejemplar de la Biblioteca Nacional de Lisboa, el cual se titula Politica angélica, Primera parte y está dedicado a Jean-Louis Faucon, presidente del Parlamento de Normandía.

6 "¿Quiên escribió la Segunda parte de la 'Hija del aire?”, Revne Belge de Philologie et d'Histoire, 54 (1976), 797-822, p. 817, nota 46: "Curiously, Enríquez Gómez published two versions of this book in the same year and with the same printing establishment..." Cuando el trabajo actual estuvo en la prensa, recibí noticias del artículo de L. REIS TORGAL, "A literatura marránica e as ediçôes duplas de António Henriques Gomes (1600-1663)" Biblos, 55 (1979), 197 228. Gracias a Reis Torgal, que las reprodujo con un breve comentario descriptivo, se puede consultar las dos versiones del texto que tiene la Biblioteca Geral da Universidade de Coimbra.

${ }^{7}$ Enríquez Gómez utiliza la Biblia protestante de Cipriano Valera (Àmsterdam, 1602), y le añade variantes propias. Puesto que su tema es la justicia 
su elogio mesiánico del rey niño, que tenía seis años en la época de la publicación, para proyectar sus ideas sobre el príncipe perfecto; y el texto está repleto de citas de aquellas autoridades antiguas que apoyan su teoría sobre la política. Pero a pesar de su contexto francés, Enríquez Gómez parece tan preocupado por España y sus instituciones como por Francia y las suyas.

Ejemplares de la obra pueden encontrarse en París (Bibliothěque Nationale, Mazarine, Sainte-Geneviễve y l'Arsenal), en Londres (British Library), y en Madrid (Biblioteca Nacional). En esos catálogos se la describe como cuarto u octavo, pero todos los ejemplares son en cuarto; y aunque a primera vista parecen idénticos, no lo son. Hay dos versiones de asignatura $S$ (pp. 137-144) con la cual termina la penúltima sección del libro. En las copias parisinas, la signatúra $\mathrm{S}$ (que denomino $A$ ) tiene una condena personal a la Inquisición española. En la copia londinense (desde ahora $B$ ), el texto de la signatura $S$ ataca la política de Felipe IV y apoya la Restauración portuguesa. Antes de examinar los diferentes textos que tenemos bajo la signatura $S$, creo conveniente presentar una descripción bibliográfica, descripción que se facilita porque en la B. N. M. se encuentran las dos versiones: R. 34579 es la copia $A$, y R. 34589 es la copia $B^{8}$.

[Portada] LVIS / DADO DE DIOS / A SAMVEL LVIS Y ANA / SAMVEL DADO DE DIOS / A ELCANA Y ANA. / DEDICADO / A LA MAGESTAD CRISTIANISSIMA / de LVIS XIV. Rey de Francia y de Navarra. / Por ANTONIO HENRIQVUEZ GOMEZ, Cauallero de la / Orden de su Mag ${ }^{d}$ Christianissima del auito de S. Miguel. /[Ex libris] A PARIS, / Par RENÉ BAVDRY, tenant son Imprimerie ruë Ticquetonne, / Auec priuilege du Roy 1645. / [Página blanca].

[Dedicatoria: $a 2^{\natural}$ [orla superior] A LA MAGESTAD / CRISTIANISSIMA / DE LVIS / DECIMO QVARTO / REY DE FRANÇIA Y DE / NAVARRA. / A. V. $M^{t}$. Dedico este brebe discurso de su / [el texto continúa hasta la mitad del reverso, donde termina con. . .] to de sus vasallos. / Humilde Vasallo de V. $\mathrm{M}^{\mathrm{i}}$. / ANTONIO HENRIQVEZ / GOMEZ. [Privilegio: $a 3^{\mathrm{r}}$ ] [orla superior] / EXTRAICT DV PRIVILEGE / du Roy. / LOVIS

y puesto que Luis XIII es llamado "Le Juste", añade la palabra "justo" a la cita inicial en el primer capítulo: "Hubo un varón justo de Ramathaim de Sophim. ..", Samuel, I, 1,1.

${ }^{8}$ Agradezco a don Francisco García Graviotto, de la sección de libros raros de la Biblioteca Nacional, la ayuda que me prestó para localizar los dos volúmenes cuya existencia había pasado inadvertida hasta hoy. 
PAR LA GRACE DE DEIV / ROY DE FRANCE ET DE NAVARRE: / A nos Amez \& Feaux Conseillers, les / [el texto continúa en el reverso, donde termina] contraires. DONNE à Paris le troisiéme iour de Mars l'an / de grace mil six cens quarante cinq. Et de nostre Regne le / deuxiéme. Signe, Par le Roy en son Conseil, DENISOT. / Et scellé du grande Sceau de cire jaune.

[Texto $\mathrm{Al}^{\mathrm{r}}$ ] [a la derecha] I [orla superior] / TEXTO, / UVO VN VARON IVSTO EN / Ramathaim de Sophim, del Monte de Efraim, / que se llamaua Elcana. Samuel lib. I. / Cap. I. Vers. I. / SEÑOR. / FVE LVIS EL IVSTO, Rey Christianisimo de Françia $\mathrm{Pa}$ - / [el texto continúa hasta $\mathrm{T} 4^{\mathrm{r}}$, y termina. . .] lata sus Armas / por todo el vniberso. / FIN. / [Ex libris] / Acheue d'Imprimer le premier Octo- / bre mil six cens quarante cinq. / [Página blanca]. $4^{\circ}: a^{4}[-a 4]$ hojas preliminares, $\mathrm{A}-\mathrm{T}^{4}$ texto [ $\$ 2$ firmada (-A2, / -Q2; hoja preliminar a2 firmada $\tilde{a}$; i mal firmada $G)$ ]; 79 hojas, pp. [i-vi] preliminares, 1-151 [152] texto (p. 104 errata 84).

Título en cabeza: [v.] LVIS / [r.] DADO DE DIOS. [No hay título en cabeza en las preliminares].

[Reclamos: A4v pudo B4v TEXTO C4 $4^{v}$ DIOS, D4v se] que E4 ${ }^{v}$ lo $\mathrm{F} 4^{\mathrm{v}}$ la, $\mathrm{G} 4^{\mathrm{v}}$ de $\mathrm{H} 4^{\mathrm{v}}$ con $14^{\mathrm{v}}$ ctores $\mathrm{K} 4^{\mathrm{v}}$ canso $\mathrm{L} 4^{\mathrm{v}}$ Prin- $\mathrm{M} 4^{\mathrm{v}}$ disimular $\mathrm{N} 4^{\mathrm{v}}$ ñor $\mathrm{O} 4^{\mathrm{v}}$ agostaua, $\mathrm{P} 4^{\mathrm{v}}$ ta $\mathrm{Q}^{\mathrm{v}}$ ça $\mathrm{R} 4^{\mathrm{v}}$ de las $\mathrm{S} 4^{\mathrm{v}}$ deue.

La forma en que $B$ proviene de $A$ confirma el hecho de que hubo dos impresiones distintas de la signatura $\mathrm{S}$, y ayuda también a establecer la prioridad de $A$ sobre $B$. Aunque ambos volúmenes tienen en la impresión una palabra clave, el reclamo, al pie de la página izquierda, opuesta a la nueva signatura que debería unirse al cuerpo de la obra, la falsa signatura $S$, curiosamente, carece de la palabra deue en la página 144 , donde $S^{4-v}$ lleva a la signatura $T$. Además, las fibras del papel de la signatura $S$ en el ejemplar $B$ no son idénticas a las del resto del volumen y a las del ejemplar $A$. Análisis posteriores del papel demostraron que la signatura $S$ del ejemplar $B$ no provienen del mismo lote, y no pudieron haberse compuesto (si así ocurrió) al mismo tiempo que el resto de las páginas del volumen, hecho que atestiguan las filigranas9. Estas forman un elaborado escudo de armas con las iniciales HAV, y el diseño secundario es un pequeño racimo de

\footnotetext{
${ }^{9}$ Sobre el examen de las filigranas en el teatro del Siglo de Oro, y sobre su utilidad para fechar los materiales, véase BRUNo SCARFE, "A role for watermarks in bibliographical description with special reference to a collection of
} 
uvas en posición horizontal. Las marcas mayores y menores están distribuidas de la siguiente forma: en $A$, las páginas preliminares no tienen nada visible; en $B$ hay un pequeño racimo de uvas; la signatura A de $A$ tiene un pequeño racimo de uvas, y desde $\$ B$ hasta $\$ T$, el escudo de armas. En $B, \$ A-H$ tienen el escudo, pero la signatura $I^{3}$ tiene sólo el racimo horizontal, y el escudo reaparece en $\$ K$ - $R$ y en $T$. Las filigranas en la signatura $S$ son diferentes: $S^{1}$ y $S^{4}$ tienen un gran racimo de uvas vertical; $S^{3}$ y $S^{4}$ conservan un fragmento de la contramarca, la porción de la cresta con las iniciales HAV. Es casi imposible que una signatura tenga cuatro marcas sin que el doblez se haga de manera muy especial, lo que nos dice, claramente, que el original $A$ fue sustituido cuidadosamente por la signatura $S$ de $B$.

La forma en que se unieron las signaturas nos da información adicional para confirmar que $A$ es la versión primera y $B$ la segunda. En la unión de signaturas $\mathrm{R}$ y $\mathrm{S}$, una cita comienza en página $136\left(\mathrm{R}^{4 \cdot v}\right)$, y continúa nueve líneas más en $A$; pero en $B$, la misma cita se corta dos líneas después de repente en la mitad de una línea, recurso evidente para justificar el nuevo número de líneas y acomodar la extensa interpolación. Los ojos del lector se detienen dudosos ante un espacio en blanco poco usual, que se hace más evidente a causa de que hay otra desviación del formato normal: el primer párrafo que sigue comienza justo al margen. Hay diferencias también en la unión de las signaturas $\mathrm{S}$ y $\mathrm{T}$. En la página $144\left(\mathrm{~S}^{4 \cdot v}\right), A$ tiene una serie de preguntas cuyas respuestas comienzan con un retórico "no obstante" que continúan sin tropiezos hasta la frase verbal del final que une las dos signaturas: "Se deue (p. 144) tractar (p. 145)". Al contrario, B termina de manera torpe: después de una página en que se discute por extenso sobre el amor y la lealtad, la signatura $\mathrm{S}$ se une a $\mathrm{T}$ en la frase "con otra fe / deue tractar". Además, falta una línea en página 144 de $B$ (23 líneas en vez de 24 ), y, como dije, falta la marca suscrita, en este caso, "deue".

En el cuerpo de $B$ encontramos otra incoherencia: normalmente, cuando Enríquez Gómez se apoya en autoridades umversalmente reconocidas procura equilibrar una cita del Antiguo Testamento con una de fuentes cristianas; en este caso, sin embargo, aparte de David y Salomón, la única autoridad que cita abiertamente es Aristóteles.

Spanish dramatics items", Bibliographical Society of Australia and New Zealand Bulletin, 3 (1978), 85-101. Quiero agradecer también al señor Scarfe, de La Trobe University (Australia), por el tiempo y la paciencia con que me ayudó en mi proyecto en la Biblioteca Nacional. 
Hay, pues, suficientes pruebas para determinar la prioridad de $A$ sobre $B$; pero, ¿qué mensajes quiere comunicar el autor, y qué le llevó a substituir uno por el otro?

La sección en la que aparece la signatura S (pp. 133-145), comienza con una cita de Samuel I, 7, 3:

Y HABLÓ SAMVEL A TODA La Casa de Ysrrael diciendo: si queréis de todo vuestro coracón bolueros al Señor, Quitad los Dioses agenos, o Astharoth de entre vosotros, y preparad vuestro coraçón para seruir a Dios sólo, y él os librará de manos de los Philisteos ${ }^{10}$.

El mensaje de Samuel está dirigido a los israelitas, a quienes procura volver a la verdadera fe, para alejarlos de sus enemigos; pero las ideas que se exponen en la glosa que sigue son más bien civiles que religiosas, y se refieren a la conducta de los funcionarios públicos, a quienes el gobernante debe escoger con buen juicio: "El príncipe Sabio deue amonestar a las principales cabecas del ymperio, no sólo a que amen la justicia en público, sino que la guarden siempre, que se desnuden de ambición" ( $p$. 134).

Los ministros deben ser devotos de la justicia y carecer de ambición (a la que llama "Astharoth [falso Dios] de los ministros ynjustos"); deben también evitar el beneficio propio, io que inevitablemente conduce a errores de juicio: "apartad de vuestro espíritu el interés particular y no erraréis los juicios" (p. 135).

Vuelve luego su atención a los jueces ("Iuezes del Mundo, quitad, quitad, dize Dios, á Astharoth de entre vosotros..."), y recuerda en seguida a todos los jefes terrenales que reciben su mandato de Dios:

Oyd Reyes, aprended juezes de la tie rra, dadme oýdos los que gober. náis los pueblos, y los que honráis la multitud de las gentes De Dios tenéis el Señorio, y la potestad del altísimo (pp. 136-137).

En este punto, página 137, línea 2, difieren los textos $A$ y $B$. $A$ continúa la no reconocida cita bíblica, con su amenaza de retribución divina:

El hará ynquisición de Vuestros juicios, y de vuestras obras, y escudriñará vuestros consejos. Por que siendo Ministros del Reyno no jusgasteis Rectamente, ni guardasteis la ley, ni caminasteis conforme a su consejo Espantoso y de repente vendrá sobre vosotros el juicio del todo poderoso: $A$ vosotros tyrannos se endereçan mis palabras, con vosotros hablo: Espantosa palabra es la que dice, EL HARA INQVISICION DE VUESTROS UICIOS (p. 137) ${ }^{11}$.

${ }^{10}$ Conservo la ortografía, sólo añado la acentuación moderna.

${ }^{11}$ La cita es en realidad una paráfrasis de estos versículos del Libro de la 
La estruendosa repetición de "Él hará inquisición de vuestros juicios" señala que el tema no se refiere ya a los jueces en general, sino a los inquisidores españoles en particular, que son objeto de la ira de Dios.

Aunque Enríquez Gómez está de acuerdo en que la Inquisición se instituyó para hacer y conservar conversos para la Iglesia, presenta dos razones para limitar su poder. Su primer argumento es religioso: como institución, sus prácticas son contrarias a la doctrina cristiana; su segundo argumento es civil y pragmático: la mala administración de sus actividades son, probadamente, destructivas para el reino. Las prácticas que más critica son los juicios secretos y la deshonra pública, la exclusión de los puestos públicos $\mathrm{y}$, sobre todo, la confiscación de bienes, acto que considera "arbitrio inventado por el demonio" (p. 141) ${ }^{12}$.

Afirma Enríquez Gómez que se mueve a la gente por amor, no por la fuerza: "la Doctrina sancta se pega más al coraçón con el amor que con el Rigor" (p. 138). La violencia endurece la resistencia y, en último término, vence al propósito para el que fue establecida, alejando a los individuos de la fe a la que quería atraer.

La Iglesia necesita seguir el ejemplo de Dios, que es justo, piadoso y perdona a los pecadores: "no se perdonan siete veces sino setenta veces como consta del Evangelio y doctrina apostó-

Sabiduría: "Buelve a su tema principal de exhortar a los governadores de mundo al estudio de la verdadera Sabiduría, amenazándoles con el riguroso juyzio que los espera, si la dexaren - 1) Mejor es la Sabiduría que las fuerças y el varón prudente que el fuerte. 2) Oyd (pues) ó Reyes, y entendéis, y aprended juezes de todos los términos de la tierra. 3) Dad oýdos los que mandáys a los pueblos, y los celos honrráys con la multitud de las gentes. 4) Porque de Dios tenéys el señorío, y la potestad por el altíssimo; que hará inquisición en vuestras obras, y escudriñará vuestros consejos. 5) Porque siendo ministros de su Reyno no jusgasteis rectamente; ni guardasteis la Ley, ni caminasteis conforme a su consejo. 6) Espantoso y de repente vendrá sobre vosotros, porque duro juyzio hecho sobre los que presiden. 7) A vosotros pues tiranos se enderezan mis palabras, porque aprendáys sabiduría y no trompecéys". Enríquez Gómez se refiere a menudo al Libro de la Sabiduría para unir el "intelecto" o la "Sabiduría de Salomón" del Antiguo Testamento con el "Espiritu Santo" del Nuevo. A veces, el español se siente verdaderamente iluminado por la Sabiduría de Dios.

${ }^{12}$ Enríquez Gómez continúa sus ataques al Santo Oficio en su obra Inquisiçion de Luzifer y visita de todos los diablos, un manuscrito inédito que, generosamente, me permitió leer Maxim P. A. Kerkhof; véase en Sef, 38 (1978), 318-331, su valioso artículo sobre el descubrimiento de este manuscrito. 
lica" (p. 140). Jean Bodin se une a San Crisóstomo y San Agustín al aconsejar la conversión por medio del amor.

Aristóteles sirve a Enríquez Gómez para condenar al Santo Oficio: por razón de estado al impedir que ciudadanos capaces entren al servicio público, y, en último al quitarles la vida, sólo se consigue la ruina de la República.

...y la Raçón de estado condena este modo de gobierno, por que según la opinión y parecer de Aristóteles, no ay medio más perjudicial para la república, que escluyr de honor a los Vasallos (p. 138). .. porque no ay más seguro medio para la Ruina, que deshonrar, desterrar, talar, quemar y perseguir a sangre y fuego los vasallos (p. 140).

La piedad y la justicia son virtudes del príncipe cristiano, a quien Enríquez Gómez aconseja que premie, no que castigue a sus súbditos.

Aunque Enríquez Gómez reconoce el derecho del estado de limitar la libertad de culto, siente que esa política alienta la calumnia y permite la proliferación de malsines:

Es linaje de tiranía abrir puerta a la calunia de los Reynos adonde no se permitte Religión estraña por que sería yr poco a poco aruynando el ymperio y dando ocasión a los malsines de ser homiçidas de los fieles (pp. 140-141).

Desde un punto de vista ideal, el reino debería permitir la diversidad de religiones, porque Dios busca almas voluntarias y el cristianismo, por sus propios méritos, atraerá a los conversos. $\mathrm{Si}$ no es así, bastará al no católico una advertencia. Para los países donde no existe la libertad de culto, Enríquez Gómez aconseja el exilio como pena máxima ${ }^{13}$, pero insiste en que les sea permitidoa los exiliados conservar sus propiedades. Para sostener su opinión, de que no hay conexión entre los pecados del espíritu y el secuestro de bienes terrenales, Enríquez Gómez se apoya en el Concilio de Toledo y en el profeta Ezequiel. De hecho, la confiscación de bienes atenta contra el séptimo mandamiento, "no hurtarás" (p. 144). Con esta insistencia en la separación de lo material y lo espiritual, termina la signatura $\mathrm{S}$ del ejemplar $A$.

\footnotetext{
${ }^{18}$ En su teatro, Enríquez Gómez apoya esa misma actitud moderada, puesto que el "malvado" de la obra recibe como castigo el exilio, no la ejecución. Así, son condenados al exilio Lisipo en Los filósofos de Grecia (Comedias escogidas, XIX, 1662), Tello en No hay poder contra el honor (Comedias escogidas, 19/2, 1652), y Tiraín en Fernán Méndez Pinto II (ed. de L. G. Cohen, F. M. Rogers y C. H. Rose, Harvard, 1974).
} 
En el ejemplar $B$, la signatura $S$ comienza en la mitad de la extensa cita sobre el castigo divino y termina de manera algo abrupta con palabras dirigidas a los reyes: "De Dios tenéis el Señorío, y la potestad del Altísimo" (p. 137). El tema que sigue trata de la política. El autor distingue primero entre la ley divina y la política humana: de esta manera rompe con el punto de vista jerárquico aceptado - la gran cadena del ser - que prevalecía en el siglo XVII en España. Sugiere luego que la gente tiene derecho a levantarse contra el conquistador o el tirano, porque la tiranía es la ruina del reino ${ }^{14}$. De ninguna manera puede el monarca heredar la tierra conquistada; así pues, el territorio que se consigue con la guerra debe devolverse al gobernante legítimo.

Enríquez Gómez describe entonces de qué manera el vencedor puede arruinar el territorio conquistado: "destruye sus nabegaciones, aflixe sus vasallos, estrecha su comercio, y se desbela en aniquilar lo que fue honrra de su corona y gloria de su Monarquía" (pp. 139-140). Ante esta devastación, el pueblo conquistado tiene la obligación de rebelarse y reinstalar a su príncipe heredero, acción que está de acuerdo con el orden natural y el divino. Más aún, otros países están obligados a prestar ayuda a esta causa, por la fuerza si es necesario, para afirmar la justicia y evitar tiranías futuras.

Luego de justificar la rebelión en general, Enríquez Gómez trata el caso concreto de Portugal, y dice: "La Aclamación que hizo Portugal en el Sereníssimo Rey don luan el quarto, pues sacudiendo el Yugo Castellano, dio la ynbestidura Real General a quien justamente le tocaba, con aplauso de todos los Príncipes de la Europa"' (p. 143). Claramente Enríquez Gómez ruega por lacausa de Portugal, afirmando la legitimidad de la casa Braganza y pidiendo a las naciones que se unan y reconozcan a la monarquía restaurada. Como propagandista, formaría opinión pública y confiaría en alterar la política, porque, dice, "los Reynos penden de la voluntad justificada en los ojos de las naciones" (p. 139). Tal es el mensaje que contiene esta sección, en la que el pensador heterodoxo expone una teoría política sorprendente en su modernidad.

Si, como parece, $A$ fue escrito antes que $B$, el orden de la composición implica un esquema de causa y efecto. Los argumentos sobre cuestiones económicas, que Enríquez Gómez presenta para limitar el poder del Santo Oficio, están relacionados

${ }^{14}$ Sin duda, Enríquez Gómez se inspiró en Les six lizres de la République de Jean Bodin (1576). 
con su propio caso. La Inquisición había perseguido a su familia y al confiscar la riqueza de sus padres le habían quitado su herencia ${ }^{15}$. Al final se vio obligado a huir. El mensaje del ejemplar $A$ se basa en experiencias personales, y está destinado a las fuerzas que, en su opinión, son culpables de su desgracia. El ejemplar $B$ es más objetivo, menos apasionado, más meditado. En Francia, sus negocios prosperaron y sus creencias religiosas eran problema suyo; allí pues, buscó los honores que se le habían negado en su patria. Allí también consideró que debía seguir apoyando la causa portuguesa. Su Triunfo Lusitano es de 1641 y celebra la llegada a Francia de los primeros embajadores portugueses después de la Restauración ${ }^{16}$; y en 1645, Enríquez Gómez se halla implicado en la nueva máquina propagandística portuguesa. No me sorprende que el manuscrito semiautógrafo de Luis dado de Dios, que descubrí en la Biblioteca Nacional de Lisboa, contenga el texto $B$, confirmando así su continua colaboración con la causa de Portugal ${ }^{17}$. Las razones de su participación no son, sin embargo, muy claras, ¿en pro de qué estaba realmente? Quizá quería vengarse del daño que España había hecho a su familia, quizá quería ser honrado, como nuevo Jeremías, profeta de destrucción. Sin embargo, una razón es clara: tanto en el ejemplar $A$ como en $B$, la signatura $\mathrm{S}$ se une a la signatura $T$, para asegurar que el premio a los súbditos afirma la lealtad: "las honrras hechas a los vasallos son los medios más seguros, más firmes y más justos para que los ánimos se emplean en el servicio de Dios y del Rey" (p. 145).

En 1677 un censor se dedicó a estudiar una lista de libros "sacados de la librería del conde de Rebolledo". Entre los prohibidos que halló se encontraban Las antigüedades de los judios, de Flavio Josefo, Diálogos de amor de León Hebreo, Orlando furioso de Ludovico Ariosto..." 18 Sin embargo, uno de los libros

${ }^{15}$ Sobre su intento de recuperar los bienes confiscados a su madre cristiana, que ya había muerto, véase A. H. N., Inquisición, "Antonio Enríquez Gómez contra Miguel Fernandez de Fonseca por 131 libras de seda", leg. 3658, núm. 16 (1624).

${ }^{16}$ Triumpho Lvsitano, recibimiento que mandó hazer su Magestad el Christianísimo Rey de Francia Luis XIII a los Embaxadores Estraordinarios del Rey D. Ivan IV de Portugal le embió al año de 1641 (Lisboa, 1641); ejemplar Harvard College Library.

${ }^{17}$ El manuscrito contiene dos obras de Enríquez Gómez: La culpa del peregrino, autógrafo, y Luis dado de Dios, en el que solamente las primeras hojas revelan la mano del autor.

${ }^{18}$ A. H. N., Censura, "Relación de algunos libros y manuscritos sacados de la librería del conde de Rebolledo", leg. 4440, núm. 2 (1677). 
aprobados era Luis dado de Dios de Enríquez Gómez. Sin duda, la estratagema de Enríquez Gómez había dado buenos resultados. A pesar de ello, aún queda la duda: ¿que versión había leído el censor?, ¿el texto $A$, donde Enríquez Gómez ataca a la Inquisición o el $B$ donde ataca al rey español y defiende a sus enemigos mientras pone en tela de juicio el "derecho divino"? 19

CONSTANCE H. ROSE

Northeastern University.

\footnotetext{
${ }^{19}$ Agradezco a MARía C. CASAdo Lobato su amplio artículo, "La biblioteca de un escritor del XVII: Bernardino de Rebolledo", $R F E$, 56 (1973), 229-328, que recibí demasiado tarde (este artículo estaba ya en prensa) para comentarlo. Sería interesante saber por qué este autor y diplomático tenía en su biblioteca obras de escritores de política sospechosa como Tácito y Enríquez Gómez.
} 